\section{Are surgical shoes providing value for money?}

\author{
Patricia S Costigan, Gavin Miller, \\ Catherine Elliott, W Angus Wallace
}

\section{Department of}

Orthopaedic and Accident

Surgery, University

Hospital, Queen's Medical

Centre, Nottingham

NG7 2UH

Patricia S Costigan, FRCSED, orthopaedic registrar Gavin Miller, FRCS, surgical senior house officer

Catherine Elliott, BA,

orthopaedic research assistant

W Angus Wallace,

FRCSEDORTH, professor

Correspondence and requests for reprints to:

Professor Wallace.

BrMed I 1989;299:950 more cosmetically acceptable to the patient. to the wearing of comfort shoes.

\section{Patients, methods, and results}

Surgical shoes are commonly prescribed by orthopaedic surgeons and rheumatologists. The shoes include both bespoke surgical shoes, which are specially designed and fitted, and "comfort shoes," which are commercially made soft leather or suede shoes and are cheaper to prescribe. Comfort shoes usually cost $40 \%$ less than bespoke shoes and appear

All patients need to be reassessed before repeat prescription to ascertain their ability to put on and remove the shoes and to note their acceptance of the shoes' appearance. Many patients now wearing bespoke footwear have deformities that are amenable

Ninety eight patients were prescribed and fitted with shoes through the NHS at the General Hospital, Nottingham, from January 1985 to December 1986. Two to three years after the original prescriptions patients were interviewed at home by two trained female interviewers. The patients were asked about their compliance, how often they wore the shoes, and whether there were any specific and general problems in wearing them. They were also asked whether they thought that the shoes were comfortable and of benefit; what they thought about the appearance of their boots or shoes; and whether other footwear, such as slippers, sandals, or other boots and shoes, was worn concurrently.

Of the 98 patients who were entered into the study, one man and six women had died, six patients were untraceable, and three patients had undergone an operation and no longer needed surgical footwear. The remaining 82 comprised 23 men and 59 women. The age range was 22 to 95 (median age 68). Eight patients had been prescribed comfort shoes and 74 bespoke shoes (table). Fourteen patients had stopped wearing their special shoes within 36 months after prescription. Fifty wearers of bespoke shoes and seven wearers of comfort shoes thought that their shoes were of benefit.

We used the technique of Klenerman and Hughes to estimate that the average day was roughly 16 hours long.' Using this method we found that almost two thirds of wearers wore their shoes regularly. Seventy five had unlimited or only slightly restricted mobility. Of the remainder, one was chairbound and seven were housebound. Forty nine wearers of bespoke shoes and all wearers of comfort shoes were so satisfied with their shoes that they would want a repeat prescription. A considerable number of patients (33) had difficulty in putting on their shoes, often requiring help, and clearly prescribers were not paying sufficient attention to the need for Velcro fasteners for some patients.

Diagnosis of conditions requiring surgical shoes

\begin{tabular}{lccc}
\hline Condition & Bespoke shoes & Comfort shoes & Total \\
\hline Osteoarthritis & 2 & & 2 \\
Rheumatoid arthritis & 2 & & 2 \\
Hallux valgus & 16 & 2 & 18 \\
Pes cavus & 3 & $1^{\star}$ & 3 \\
Congenital deformity & $9 \star$ & 1 & 2 \\
Old polio & 2 & 1 & 3 \\
Ankle problems & 2 & 1 & 4 \\
Hammer/claw toes & 3 & 2 & 23 \\
Hallux rigidus & 1 & & 14 \\
Combinations & 21 & 8 & 82 \\
Other & 14 & & \\
\hline Total & 74 & &
\end{tabular}

*One patient in this group had been prescribed both types of shoe.

\section{Comment}

Of 82 patients prescribed surgical footwear in Nottingham, 66 continued wearing their shoes after two years. But even patients who still wore their surgical shoes were often dissatisfied, the reasons being inability to fasten their shoes themselves because of problems with other joints and the poor appearance of the shoes. Better use of surgical shoes will result if Velcro fasteners are specified more often in the original prescription for patients with poor manual dexterity. In addition, patients should be shown the range of shoes available before requesting formally that a pair be made to order. It is better for the patient to reject the shoe before provision than immediately after.

We thank Mrs Swan and the appliance officers at the Nottingham hospitals and the special trustees of the Nottingham University Hospitals for their financial support.

1 Klenerman L, Hughes J. Surgical footwear: an assessment of the place of ready-made extra-depth shoes. Current Health Trends 1986;18:45-6.

(Accepted 30 August 1989)

\section{Cold injury from liquid propane}

\section{N K James, A L H Moss}

Department of Plastic and Reconstructive Surgery, Frenchay Hospital, Bristol BS16 1LE

N K James, FRCS, senior house officer

A L H Moss, FRACS, senior registrar

Correspondence to: Mr James.

BrMed J 1989:299:950-1
The danger of injury from volatile liquids such as liquid propane igniting is well known. "Burn like" injuries produced from short but direct contact are less well known. We report two cases of cold injury from liquid propane.

\section{Case 1}

A 15 year old boy was playing with a cylinder of liquid propane gas and fell with the cylinder on top of him. Some colourless liquid and white gas sprayed on to his face and hands for about 20 seconds. When he was examined in the burns unit at this hospital he had superficial "burns" to his face and right hand of $1.5 \%$ body surface area. His hand was erythematous and blistered, his face erythematous. He was treated for a thermal injury. The hand was covered with silver sulphadiazine and a polyethylene bag and was raised and mobilised. The face was treated by exposure. $\mathrm{He}$ was discharged the next day. Three weeks later an area $3 \times 4 \mathrm{~cm}$ on the dorsum of the first web space of the hand, which had not healed because of full thickness skin loss, was surgically debrided and a split skin graft applied. Six weeks after the injury his burns had fully healed and function had returned.

\section{Case 2}

A 43 year old driver transporting liquid propane gas opened the filling valve while filling the tanker and a jet of liquid propane leaked from the tank, spraying his right thigh. He was wearing overalls and a pair of jeans. He was transferred to the burns unit from the local accident unit. He had a superficial "burn" to 
the anterolateral aspect of the right thigh of $3 \%$ body surface area. The skin was erythematous and oedematous but not blistering and was treated conservatively. The wound healed within three weeks, and he was discharged with no further treatment.

\section{Comment}

Industrial and domestic use of liquid propane is increasing. Liquid propane is volatile; the boiling point at atmospheric pressure is $-44^{\circ} \mathrm{C}$. The gas is usually transported as a liquid under pressure at $-64^{\circ} \mathrm{C}$. The catastrophic consequences of igniting liquid propane have been reported.' Injuries occasionally occur in the industry, but injuries from direct contact with propane are rarely seen. Spraying liquid propane on to the skin usually causes cold injury. Hicks et al showed that spraying the skin with propane for 12 seconds caused epidermal necrosis in animals. Spraying for 30 seconds caused dermal necrosis 24 hours later, and damage to the superficial muscle was seen five days later. The tissue freezes, which leads to cell damage and vascular thrombosis-similar to frostbite but more rapid with propane.

\section{Liquid crystal thermography and $C$ reactive protein in the detection of deep venous thrombosis}

\author{
E A Thomas, M J D Cobby, E Rhys Davies, \\ W D Jeans, J T Whicher
}

\section{Department of \\ Radiodiagnosis, Bristol \\ Royal Infirmary, Bristol BS2 8HW \\ E A Thomas, FRCR, senior registrar \\ M J D Cobby, FRCR, senior registrar \\ E Rhys Davies, FRCR, professor \\ W D Jeans, FRCR, reader}

Department of Chemical Pathology, Old Medical

School, University of

Leeds, Leeds LS2 9JT

J T Whicher, MRCPATH, professor

Correspondence to: Dr Thomas. thermography has been employed, which uses simple, portable equipment. ${ }^{2}$ In a consecutive series of patients suspected of having deep venous thrombosis we examined the accuracy of liquid crystal thermography and measurement of the $C$ reactive protein concentration compared with phlebography.

\section{Patients, methods, and results}

We studied 78 patients ( 36 male, 42 female) with a mean age of 58 years (range 10-90) clinically suspected
Our two patients had what looked like a thermal injury, where the tissue feels warm and does not have to be warmed slowly as in prolonged exposure to cold. Neither patient had evidence of "frosting," and the appearance was similar to a scald.

Spilling liquid propane directly on the skin caused deep necrosis in the first patient. The liquid propane vapourised on the warm tissues, causing rapid cooling of the surrounding tissue and resulting in a deeper injury than propane gas caused in the second patient. $\mathrm{He}$ was also protected by two layers of clothing. Initially, skin loss in both patients seemed to be superficial.

Liquid propane is now used as a fuel for domestic heating systems, cars, camping, and caravaning. By law, containers for transporting liquid propane carry warnings of explosion but no warning of the danger of direct contact.

I Arturson G. The tragedy of San Juanico-the most severe LPG disaster in

2 Hicks LM, Hunt JL, Baxter CR. Liquid propane cold injury: a clinicopathologic and experimental study. F Trauma 1979;19:701-3.

Accepted 26 fuly 1989)

diffusion. The defined upper limit of the normal concentration is $<10 \mathrm{mg} / \mathrm{l}$.

Comparing the results of liquid crystal thermography with phlebography yielded 47 positive thermograms including 20 which were false positive. The thermograms were negative in 31 patients, of which five were false negative. Liquid crystal thermography therefore had a sensitivity of $84 \%$ (95\% confidence interval $72 \%$ to $96 \%)$ and a specificity of $57 \%(42 \%$ to $70 \%$ ) in detecting deep venous thrombosis.

There were 47 patients who were examined by liquid crystal thermography who also had their $C$ reactive protein concentration measured before phlebography. In 32 cases the concentration was raised, and in 14 of these the phlebogram was normal. In all but two of these patients there was an alternative explanation for the raised $C$ reactive protein value. The 15 patients with normal $\mathrm{C}$ reactive protein concentrations all had normal phlebograms. There were no false negative $\mathrm{C}$ reactive protein estimations. The $\mathrm{C}$ reactive protein concentration therefore had a sensitivity of $100 \%(95 \%$ confidence interval $78 \%$ to $100 \%$ ) and a specificity of $52 \%(34 \%$ to $70 \%)$ in detecting deep venous thrombosis. of having deep venous thrombosis. They were first examined by liquid crystal thermography and the result recorded before proceeding to phlebography. After the first 31 patients had been examined in this way subsequent patients also had blood withdrawn before the injection of contrast for estimation of the $\mathrm{C}$ reactive protein concentration.

Liquid crystal thermography was performed with a series of latex contact sheets containing organic ester derivatives which respond to different temperatures by emitting visible light of varying wavelengths and therefore different colours. ${ }^{+}$Phlebography was performed in the usual way by using non-ionic contrast medium. $\mathrm{C}$ Reactive protein was asssayed by radial immuno-

\section{Comment}

The management of suspected deep venous thrombosis is a recurrent problem, and a simple screening test to decide which patients should have more complicated, painful, and expensive examinations would be useful. We had hoped that the portable liquid crystal thermography unit would fulfil this role. ${ }^{3}$ We found, however, that its sensitivity was too low with too many false negative results.

C Reactive protein is a sensitive and reliable acute phase protein whose concentration can now be estimated rapidly and cheaply. Its concentration in plasma increases within six to eight hours after an inflammatory stimulus, peaking at around 48 hours before falling to normal with a half life of about 48 hours.' In the presence of inflammatory complications such as infection the expected fall on the third postoperative day does not occur. Steroids, oestrogens, and pregnancy have no effect on its concentration. Some diseases, such as the connective tissue diseases, osteoarthritis, and ulcerative colitis, also lack an acute phase response. 